Research Paper

\title{
Screening of efficient arbuscular mycorrhizal fungi for Azadirachta indica under nursery condition: A step towards afforestation of semi-arid region of western India
}

\author{
K. Banerjee ${ }^{1}$, M.H. Gadani ${ }^{1}$, K.K. Srivastava ${ }^{2}$, Neelam Verma ${ }^{2}$, Y.T. Jasrai ${ }^{3}$, N.K. Jain ${ }^{4}$ \\ ${ }^{1}$ Gujarat Forest Research Institute, Research Division, Gujarat, India. \\ ${ }^{2}$ Arid Forest Research Institute, Rajasthan, India. \\ ${ }^{3}$ Dept. of Botany, University School of Sciences, Gujarat University, Gujarat, India. \\ ${ }^{4}$ Department of Life Sciences, University School of Sciences, Gujarat University, Gujarat, India.
}

Submitted: June 10, 2011; Approved: June 5, 2012.

\begin{abstract}
To optimize nursery practices for efficient plant production procedures and to keep up to the ever growing demand of seedlings, identification of the most suitable species of arbuscular mycorrhizal fungi (AMF), specific for a given tree species, is clearly a necessary task. Sixty days old seedlings of Neem (Azadirachta indica A. Juss) raised in root trainers were inoculated with six species of AMF and a mixed inoculum (consortia) and kept in green house. Performances of the treatments on this tree species were evaluated in terms of growth parameters like plant height shoot collar diameter, biomass and phosphorous uptake capabilities. Significant and varied increase in the growth parameters and phosphorous uptake was observed for most of the AMF species against control. Consortia culture was found to be the best suited AMF treatment for A.indica, while Glomus intraradices and Glomus mosseae were the best performing single species cultures. It is the first time in the state of Gujarat that a wide variety of AMF species, isolated from the typical semi-arid region of western India, were tested for the best growth performance with one of the most important tree species for the concerned region.
\end{abstract}

Key words: arbuscular mycorrhizal fungi, Neem, Glomus mosseae, Glomus intraradices.

\section{Introduction}

Neem (Azadirachta indica A. Juss) is one of the most important tree species in the western part of the Indian subcontinent, especially in the state of Gujarat. Every year a large target is set to the Gujarat State Forest Department to produce seedlings of this tree species in abundance in the nursery to meet various objectives including a rigorous afforestation program. Attempts are often made to reclaim degraded soils and wastelands of this part of the country with these nursery raised seedlings as a part of these activities. Neem which is an important multipurpose tree species has been observed to be well suited to all kinds of lands and wide range of environment (Tewari, 1992), especially tolerant to poor soils of arid and semi arid regions (Benge, 1989) and hence makes an obvious choice for the mission.
Rapid production of high quality seedlings in nurseries is a pre-requisite for any aggressive re-forestation program, but it has been observed earlier (Michelsen, 1992) that optimal nursery conditions can hardly be achieved for quality seedling production. Moreover, there may be severe shortage in microbial populations including arbuscular mycorrhizal fungi (AMF) owing to the fact that soils used in the nursery are often collected from barren surroundings, subsoil or may have been stored for a long time (Muthukumar et al., 2001). AMF is an imperative component of soil microbial biomass influencing essential processes at the plant+soil interface (Harley and Smith, 1983; Bagyaraj, 1984; Rajan et al., 2000). To counteract the transplantation shock seedlings of tropical tree species raised in the nursery may need to be associated with AMF (Urgiles et al., 2009) besides gaining several conventional benefits of AMF association in terms of growth and nutri-

Send correspondence to K. Banerjee. Gujarat Forest Research Institute, Research Division, ’j’ Road, Sector 30, Gandhinagar 382 020, Gujarat, India. E-mail: kasturi_282004@yahoo.co.in. 
ent uptake. It may further be noted that in vitro culture of $\mathrm{AMF}$ is rather cumbersome and hence a large quantity of inoculum production is highly cost ineffective to warrant inoculation of the soil under field condition. Inoculation in the nursery, on the contrary, may provide dual benefits of being inexpensive and providing better vigour of seedlings to cope with transplantation.

AMF are rather obligate symbionts and their role in plant growth and nutrient uptake is well documented (Srinivas et al., 1988; Arya, 1999; Sumana and Bagyaraj, 1999; Garg et al., 1999; Kumar et al., 2000; Bhattacharya et al., 2000; Sharma and Adholeya, 2000; Prasad, 2002). It has been observed that roots of Neem are profusely colonized by AMF and it is considered as a highly mycorrhizal dependent tree species (Habte et al., 1993).

Most AMF can form association with susceptible plants, regardless of the genetic diversity or geographical distribution of the two symbionts. Furthermore, the formation and function of mycorrhizas can be quite variable among fungal species and even among isolates of the same species (Smith and Smith, 1997; Smith et al., 2000). A fairly wide range of functional diversity in AMF could have lead to the observed differences among fungal species in the manner they facilitate host plants in resisting biotic and abiotic stress (Smith and Read, 1997). It is, however, more conventional to define in terms of plant growth responses, which may vary monotonically from unprecedented increment in growth to neutral depending on the particular plant-fungus combinations and environmental conditions (Johnson et al., 1997). Plant fungus combinations that promote optimum plant growth are believed to be those that provide the greatest amount of $\mathrm{Pi}$ to the plant for the least amount of photosynthate transferred to the fungus (Burleigh et al., 2002). Further, it was reported that different species of AMF differ to the extent by which they increase nutrient uptake and plant growth (Bagyaraj et al., 1989). Hence, the need for selecting efficient AMF that can be used for inoculating different plants was emphasized (Bagyaraj et al., 1989). Most of the studies performed earlier in this context are either highly region specific or symbionts specific and knowledge base is far from sufficient as far as the western part of India is concerned.

The objective of the present study was to screen the AMF species, isolated from the semi-arid region and local AMF isolated from the rhizosphere of Neem in order to select an efficient inoculant species of AMF for Neem in nurseries.

\section{Materials and Methods}

\section{Experimental site}

The study was conducted at the forest nursery of Basan Research range, Gandhinagar, Gujarat (2313' N: $72^{\circ} 41^{\prime}$ E, altitude: $80 \mathrm{~m}$ ). The Gandhinagar district has multi seasonal climate with an average precipitation of 667 mm. Minimum temperature records $7.5^{\circ} \mathrm{C}$ in winter and maximum temperature records $45{ }^{\circ} \mathrm{C}$ in summer. [Gandhinagar District Panchayat, Gujarat Government 200809]. Plants were grown using a $14 \mathrm{~h}$ day $/ 10 \mathrm{~h}$ night cycle.

\section{Plant and fungus material}

Seeds of Neem were procured from Basan research range, Forest Department of Gujarat. Seeds were collected from candidate plus trees (CPT) of Gandhinagar research range. Sand+soil based pure cultures of Glomus intraradices, Glomus reticulatum, Glomus fasciculatun, Glomus mosseae and Glomus constrictum were obtained from Arid Forest Research institute (AFRI), Government of India, Jodhpur, Rajasthan. Pure cultures of Glomus aggregatum and mixed inoculum (consortia) culture were prepared from soil samples collected from nearby plot of Neem plantation at Basan research Range. The composition of consortia was identified to be Glomus (79\%), Gigasspora (8\%), Sclerocystis (5.3\%), Scutellospora (5\%), Acaulospora (2.7\%) following Schenck and Perez (1987). These fungi were multiplied as pot culture using sterilized sand:soil mix $(1: 2 \mathrm{v} / \mathrm{v})$ as the substrate and Zea mays as the host in a green house. After 120 days of growth, shoots of Zea mays were severed and the substrate containing hyphae, spores and root bits was air-dried and used as the inoculum.

\section{Seedling production}

Seeds were sown in plastic trays filled with sterilized sand: soil mixture $(1: 2 \mathrm{v} / \mathrm{v})$. Sterilization was done by autoclaving the sand:soil mixture three times at $121^{\circ} \mathrm{C}$ and 15 psi pressure for $60 \mathrm{~min}$ at an interval of one day. Seeds were germinated in the germination tray within 8 days and the seedlings were maintained there for another 3 days. At the end of 11 days the healthy seedlings of uniform length $(2.5 \mathrm{~cm})$ were selected and transferred to root trainers of 150 cc capacity containing unsterile nursery soil:sand:compost $(2: 1: 1 \mathrm{v} / \mathrm{v})$. The soil had a $\mathrm{pH}$ of 8.4 (1: 1 soil to water extract ratio), EC- $0.24 \mathrm{mS} \mathrm{cm}^{-1}$ and organic carbon- $0.29 \%$ (Walkley and Black, 1934). It contained $12.5 \mathrm{mg} \mathrm{kg}^{-1}$ available P (Olsen et al., 1954), $180.35 \mathrm{mg} \mathrm{kg}^{-1}$ available K Ghosh et al., 1983), and an indigenous AMF population of 206 spores $100 \mathrm{~g}^{-1}$ of soil and an inoculum potential of 900 infective propagules $\mathrm{g}^{-1}$ soil (Porter, 1979). The seedlings were maintained there for 75 days.

\section{AM inoculation}

Two month old seedlings were inoculated with seven AMF inocula viz. $G$. intraradices, $G$. reticulatum, $G$. fasciculatum, G. mosseae, G. constrictum, G. aggregatum and consortia. On the basis of their abundance in these soil types, emphasis was given on the Glomus species while selecting the AMF isolates. Each seedling in the root trainer was inoculated near the root zone at the rate of 10,000 infective propagules. Same amount of sterile inoculum, 
which had been autoclaved thrice at $121^{\circ} \mathrm{C}$ and 15 psi pressure for $60 \mathrm{~min}$ at an interval of one day, was applied to the control (non-noculated with AMF) seedlings. The experiment was laid out in completely randomized design (CRD). There were four replicates for each of the eight treatments (including control) with 24 plants per replicate, total 768 plants. Watering was done as per requirement.

After 75 days seedlings were transferred from root trainers to polybags containing $1.5 \mathrm{~kg}$ of same nursery soil: sand: compost mixture and maintained under ambient condition with normal watering in the green house. Each bag contained one seedling. The bags were rearranged every 15 days to ensure uniform growth conditions.

\section{Data collection}

Plant height was measured from soil surface to the growing tip of the plant. Collar diameter was measured 1 $\mathrm{cm}$ above the soil surface using vernier callipers. These two parameters were recorded bimonthly after plantation. However, only observations recorded at the end of the experiment are presented in this paper. Plants were harvested after 210 days. At harvest, observations on morpho-physiological parameters like, plant fresh weight, plant dry weight, root colonization, spore density and phosphorous uptake were recorded.

Plant dry weight was determined after drying the plant sample at $80^{\circ} \mathrm{C}$ to a constant weight in a hot air oven.

The AM fungal spores were isolated from the rootzone soil by wet sieving and decanting technique (Gerdemann and Nicolson, 1963), examined under stereo zoom microscope (Leica ${ }^{\circledR}$ Combistereo), counted and expressed as spore density. For examining root colonization, roots of seedlings receiving different AMF treatments were separated from soil samples and processed to investigate the mode of colonization by AMF. The roots were cut into $1 \mathrm{~cm}$ pieces, cleared and stained with trypan blue (Phillips and Hayman, 1970). 100 root pieces were selected randomly, mounted in lactophenol, and examined for AM fungal infection by using compound microscope. The Percentage of root colonization was determined according to Giovannetti and Mosse (Giovannetti and Mosse, 1980).

\section{Phosphorus estimation}

Grinded and sieved $(<2 \mathrm{~mm})$ plant samples were digested, using tri-acid mixture as described in (Jackson, 1973). $0.5 \mathrm{~g}$ plant samples were placed in $100 \mathrm{~mL}$ cooled conical flask and then $5 \mathrm{~mL}$ of tri-acid mixture $\left(\mathrm{HNO}_{3}\right.$ : $\left.\mathrm{H}_{2} \mathrm{SO}_{4}: \mathrm{HClO}_{4}\right)$, (9:2:1) was added. The digestion was carried out at 180 to $200{ }^{\circ} \mathrm{C}$ until a clear solution remained after the acids were largely volatilised. After complete digestion the final volume was made up to $50 \mathrm{~mL}$. For phosphorus estimation $10 \mathrm{~mL}$ of digested plant material was placed in $50 \mathrm{~mL}$ volumetric flask, with $20 \mathrm{~mL}$ distilled water and $15 \mathrm{~mL}$ mixture of dilute $\mathrm{HNO}_{3}$, Ammonium molybdate $(5 \%)$ and Ammonium metavanadate $(0.25 \%)$ in equal proportions (1:1:1). The volume was made up to $50 \mathrm{~mL}$ with distilled water and the yellow colour intensity was read at $485 \mathrm{~nm}$ using Systronics Vis Spectrophotometer166.

\section{Statistical analysis}

The final data was subjected to one - way Analysis of Variance (ANOVA). Based on the outcome of ANOVA on all data, post-hoc analysis had been performed in the form of Duncan's Multiple Range test (Duncan, 1955) to separate the means. Linear regression analysis was used to assess the relationship between AMF colonization, growth parameters and phosphorous uptake.

\section{Results}

The response of Neem to inoculation with different AMF treatments showed certain distinctive features. Results of height, plant biomass (fresh and dry) and collar diameter are shown in Table 1. Significantly longer plant height had been observed for all the treatments against control. Plant height had increased maximally for consortia (mixed inoculum) (41.06\%) against the control. Consortia

Table 1 - Effect of different treatments on growth of $A$. indica.

\begin{tabular}{lcccc}
\hline Treatment & Plant height* $(\mathrm{cm})$ & Fresh weight* $(\mathrm{g})$ & Dry weight* $(\mathrm{g})$ & Collar diameter* $(\mathrm{mm})$ \\
\hline Control & $20.19 \mathrm{e}$ & $49.00 \mathrm{ef}$ & $17.00 \mathrm{def}$ & $2.47 \mathrm{~b}$ \\
G. aggregatum & $25.48 \mathrm{~d}$ & $44.75 \mathrm{fg}$ & $17.00 \mathrm{de}$ & $3.22 \mathrm{a}$ \\
G. fasciculatum & $26.33 \mathrm{~cd}$ & $47.75 \mathrm{efg}$ & $16.00 \mathrm{efg}$ & $3.57 \mathrm{a}$ \\
G. constrictum & $26.43 \mathrm{bcd}$ & $52.50 \mathrm{de}$ & $16.00 \mathrm{efg}$ & $3.31 \mathrm{a}$ \\
G. reticulatum & $26.45 \mathrm{bcd}$ & $57.25 \mathrm{~d}$ & $18.50 \mathrm{~d}$ & $3.47 \mathrm{a}$ \\
G. mosseae & $27.06 \mathrm{bc}$ & $73.00 \mathrm{abc}$ & $23.75 \mathrm{bc}$ & $3.24 \mathrm{a}$ \\
G. intraradices & $27.40 \mathrm{~b}$ & $73.25 \mathrm{ab}$ & $24.75 \mathrm{ab}$ & $3.36 \mathrm{a}$ \\
Consortia & $28.48 \mathrm{a}$ & $75.25 \mathrm{a}$ & $26.50 \mathrm{a}$ & $3.39 \mathrm{a}$ \\
\hline
\end{tabular}

*Mean of 60 observations.

Values without common letters differ significantly at $\mathrm{p}=0.05$.

Significance tested by Duncan's Multiple Range Test. 
had been closely followed by $G$. intraradices $(35.7 \%)$ and G. mosseae (34\%). G. reticulatum, G. constrictum and $G$. fasciculatum were at par with each other. G. aggregatum and $G$. fasciculatum varied significantly with $G$. intraradices while significant variation had also been observed between G. aggregatum and G. mosseae. Collar diameter increased significantly in all AMF treated plants as compared to control. However, no significant variation had been observed among the other treatments. Collar diameter had increased maximally by AM inoculant $G$. fasciculatum (44.53\%) against control. Inoculated plants exhibited significant increase in plant biomass with respect to untreated controls. Majority of the treatments except G. aggregatum, G. fasciculatum and G. constrictum had shown significant increase in plant fresh weight as compared to control. Consortia treatment had shown maximum increase (53.57\%). Consortia, G. intraradices and G. mosseae varied significantly with respect to $G$. reticulatum, $G$. constrictum, $G$. fasciculatum and G. aggregatum. However, no significant difference had been observed among Consortia, $G$. intraradices and $G$. mosseae as well as between $G$. fasciculatum and G. aggregatum. With respect to dry weight, only Consortia, G. intraradices and G. mosseae varied significantly from the control. Maximum increase in plant dry weight had been observed for Consortia (56\%). Performance of consortia, G. intraradices and G. mosseae are rather similar.

AMF inoculation in Neem seedlings had exhibited significant influence on uptake of phosphorous. Plants inoculated with G. intraradices and G. fasciculatum, showed significantly higher $\mathrm{P}$ concentration in leaves than noninoculated control, while, for G. reticulatum, G. mosseae, G. constrictum and control similar responses had been recorded (Table 2). Minimum P concentration in leaves had been observed for $G$. aggregatum.

Microscopic examination of stained roots had shown colonization with all the species of AMF tested, as shown

Table 2 - Effect of different treatments on phosphorous concentration in leaves of $A$. indica.

\begin{tabular}{lc}
\hline Treatment & A. indica \\
\cline { 2 - 2 } Control & Phosphorous concentration in leaves*(\%) \\
Consortia & $0.10 \mathrm{cde}$ \\
G. aggregatum & $0.07 \mathrm{efg}$ \\
G. constrictum & $0.04 \mathrm{~g}$ \\
G. mosseae & $0.10 \mathrm{cdef}$ \\
G. fasciculatum & $0.11 \mathrm{~cd}$ \\
G. reticulatum & $0.21 \mathrm{ab}$ \\
G. intraradices & $0.11 \mathrm{c}$ \\
\hline
\end{tabular}

*Mean of 4 observations.

Values without common letters differ significantly at $\mathrm{p}=0.05$.

Significance tested by Duncan's Multiple Range Test. in Table 3. Hyphal structures were found in abundance in plant root samples. All the treatments varied significantly with the control plants both in case of root colonization and spore density. Highest root colonization percentage $(97.5 \%)$ was recorded with $G$. intraradices as compared to $61 \%$ in non-inoculated control. At the end of the experiment, maximum AMF spore count was recorded for the treatment G. mosseae (630 $100 \mathrm{~g}^{-1}$ of soil) showing its better proliferating ability as compared to other AMF (Table 3).

High correlation $(r=0.92)$ was observed between percentage root colonization and plant height. Phosphorous concentration in leaves was highly correlated $(r=0.82)$ with plant dry weight.

\section{Discussion}

The data acquired from nursery trial undoubtedly gave a clear evidence of positive response of Neem towards mycorrhization by AMF. This work may prove to be essential for implementation of AMF inoculations in the Gujarat state forest nurseries much more effectively and as a routine process. Inoculation with different species of AMF resulted in the improvement of growth and nutrient uptake to different extent. AMF species selected for the study were given preference on the basis of their abundance in rhizosphere soil of Neem present in arid and semi-arid soils of western India (Mohan and Verma, 1995; Pande and Tarafdar, 2004). Those AMF species were given preference for inoculation purpose in view of their higher probability of symbiotic association with Neem.

From the outcome of the trial it can be inferred that AMF inoculation in unsterile soil definitely boosted the growth of the seedlings, as previously reported from other plant species (Michelsen, 1993; Vasanthakrishna et al., 1994). In general it had been observed that significant growth and nutrient uptake efficiency were obtained when the number of infective propagules and/or spore density

Table 3 - Effect of different treatments on root colonization and spore number.

\begin{tabular}{lcc}
\hline Treatment & $\begin{array}{c}\text { Root colonization* } \\
(\%)\end{array}$ & $\begin{array}{c}\text { Spore number/100 g } \\
\text { soil* }\end{array}$ \\
\hline Control & $61 \mathrm{c}$ & $271 \mathrm{~d}$ \\
Consortia & $90 \mathrm{ab}$ & $562 \mathrm{abc}$ \\
G. aggregatum & $86.5 \mathrm{~b}$ & $514 \mathrm{c}$ \\
G. constrictum & $84 \mathrm{~b}$ & $596 \mathrm{ab}$ \\
G. mosseae & $93 \mathrm{ab}$ & $630 \mathrm{a}$ \\
G. fasciculatum & $88 \mathrm{ab}$ & $510 \mathrm{c}$ \\
G. reticulatum & $85 \mathrm{~b}$ & $555 \mathrm{abc}$ \\
G. intraradices & $97.5 \mathrm{a}$ & $557 \mathrm{abc}$ \\
\hline
\end{tabular}

* Mean of 8 observations.

Values without common letters differ significantly at $\mathrm{p}=0.05$.

Significance tested by Duncan's Multiple Range Test. 
was low in the soil (Reena and Bagyaraj, 1990). However, the soil used in this study was having a considerable spore population (219 spores $100 \mathrm{~g}^{-1}$ ). Hence, the improved effect of inoculation in the unsterilized substrate can be attributed to the ineffectiveness of the indigenous AMF, in agreement with the earlier findings (Bagyaraj et al., 1989; Reena and Bagyaraj, 1990) and better competitive ability of the introduced AMF over the native AMF in colonizing the roots. Presumably the indigenous inoculum level of AMF was inadequate to support plant growth to the extent as observed in the presence of an additional mycorrhizal inoculum.

$G$. intraradices and $G$. mosseae were found to be the best single species cultures for Neem in terms of the growth parameters, AMF colonization and spore density. This is in contrast with the earlier findings (Prasad, 2002) where $G$. fasciculatum had been screened as the best suited species for Neem. Improved growth parameters in plants are often complemented by enriched nutritional whereabouts (Jeffries, 1987). In case of $\mathrm{P}$ uptake, G. intraradices was closely followed by $G$. fasciculatum. This also emphasizes the importance of host specificity for determining the role of AMF. A rather wide range of variation in the symbiotic capacity of all AMF inoculants with respect to this particular tree species concerned was observed. Relatively higher P concentration $(0.23 \%)$ in leaves had been recorded for $G$. intraradices in our case than that recorded $(0.126 \%)$ by Muthukumar et al. (2001), in shoot at 120 days after transplantation. In any case, mixed inoculum (consortia) showed the best performance in terms of plant height and plant biomass (Table 4). The success of a mixed inoculum depends largely on the nature of competition between endophytes. The risk involved in this case is that the competition may decrease the growth response that a single endophyte would have produced. It can be noted that several factors including soil pH, (Koomen, et al., 1987), soil $\mathrm{N}$ and P concentration (Satir and Duniwav, 1982), soil moisture and temperature (Satir and Duniwav, 1982) may influence the rate of infection and the effect of the competitive fungi on the growth of the host plant. In the present experiment, competition among constituent species of AMF in consortia did not exhibited any decrement in growth response, instead, the particular constituent species in consortia were probably more successful in enhancing plant growth and showed better competitive ability against any other single species of AMF. This agrees with the result of Daft and Hogath (1983), who found better consistency in growth responses of plants to triple and quadruple inocula as compared to other treatments, especially under unpredicted and unsterilized soil conditions (Koomen et al., 1987).

According to the results of this study, it can be noted that a definitive coherence was observed between AMF root colonization and plant growth parameters. This supports the fact that higher root colonization allows more host-fungus contact and the exchange of nutrients helps in better growth (Mallesha and Bagyaraj, 1990). AMF may 
differ in their symbiotic effectiveness, which depends on their preference for particular soils or host plant specificity (Dhillon, 1992), direct ability to stimulate plant growth (Abbott and Robson, 1978; Govinda Rao et al., 1983), rate of infection (Rajan et al., 2000; Abbott and Robson, 1982; Miller et al., 1987) and competitive ability (Michelsen, 1993). Increased $P$ uptake in AMF treated plants was observed. This may be attributed to increased absorption through extramatrical hyphae of AMF or the enhanced growth of AMF roots may have facilitated the $\mathrm{P}$ absorption from soil.

From the above trial, it can be summarized that for $A$. indica, consortia, with the composition specified in this work, has performed best in terms of plant height and plant biomass followed by $G$. intraradices. However, $G$. intraradices turned out to be best in case of P uptake and root colonization. Such trials should be repeated in future to further streamline the best available growth boosting AMF species for each particular forest tree species. Thereafter such treatments with AMF can be adopted as a regular practice at the nurseries of Gujarat for raising specified forest tree species. This approach will surely help realizing the uphill task of aggressive reforestation of this semi-arid part of the country.

\section{Acknowledgement}

This study was funded by the Gujarat State Biotechnology Mission, Gandhinagar, Gujarat, India. The authors (KB and MHG) would like to acknowledge Dr. H.S. Singh, Mr. R.N. Tripathi, Mr. S.P. Sisodiya, Dr. B. H. Patel, Ms. Shruti Kaila and Ms. Nisha D. Goswami for many useful discussions.

\section{References}

Abbott LK, Robson AD (1978) Growth of subterranean clover in relation to formation of endomycorrhizas by introduced and indigenous fungi in a field soil. New Phyto 81:575-585.

Abbott LK, Robson AD (1982) The role of vesicular arbuscular mycorrhizal fungi and selection of fungi for inoculation. Aust J Agric Res 33:389-408.

Arya A (1999) Application of AM fungi to increase biomass of Neem seedlings. In: Proceedings of the National Conference on Mycorrhiza, Barkatulla University, Bhopal, pp 71.

Bagyaraj DJ (1984) Biological interactions with VA mycorrhizal fungi. In: Powell CL, Bagyaraj DJ (eds) VA Mycorrhiza. CRC Press, Boca Raton, pp 131-153.

Bagyaraj DJ, Byra Reddy MS, Nalini PA (1989) Selection of an efficient inoculant VA mycorrhizal fungus for Leucaena. For Ecol Manag 27:81-85.

Benge MD (1989) Cultivation and propagation of the neem tree. In: Jacobson M. (ed) Focus on Phyytochemical Pesticides Vol. 1. The Neem Tree. CRC Press Inc., Boca Raton, pp $1-18$.

Bhattacharya PM, Misra D, Saha F, Chaudhury S (2000) Arbuscular Mycorrhizal dependency of Eucalyptus tereticornis Sm: how real is it? Mycorrhiza News 12:11-15.
Burleigh SH, Cavagnaro T, Jakobsen I (2002) Functional diversity of arbuscular mycorrhizas extends to the expression of plant genes involved in P nutrition. J Exp Bot 53:1593-1601.

Daft MJ, Hogarth BG (1983) Competitive interactions amongst four species of Glomus on maize and onion. Trans Br Mycol Soc 80:339-345.

Dhillon SS (1992) Dual inoculation of pretransplant stage Oryza sativa L. plants with indigenous vesicular arbuscular mycorrhizal fungi and fluorescent Pseudomonas spp. Biol Fert Soils 13:147-151.

Duncan DM (1955) Multiple range and multiple tests. Biometrics 42:1-42.

Garg RK, Pandey A, Goyal D, Sharma RK (1999) Effect of VAM inoculations on the growth of nursery seedlings of Eucalyptus tereticornis in different geoclimatic conditions. Indian Forester 125:684-689.

Gerdemann JW, Nicolson TH (1963) Spores of mycorrhizal endogone extracted from soil by wet sieving and decanting. Trans Br Mycol Soc 46:235-244.

Ghosh AB, Bajaj JC, Hassan R, Singh D (1983) Soil and water testing methods - A laboratory manual. IARI, New Delhi.

Giovannetti M, Mosse B (1980) An evaluation of techniques to measure vesicular-arbuscular infection in roots. New Phytol 84:489-500.

Govinda Rao YS, Bagyaraj DJ, Rai PV (1983) Selection of an efficient VA mycorrhizal fungus for finger millet. Zentralbl Mikrobiol 138:415-419.

Habte M, Muruleedhara BN, Ikawa H (1993) Response of neem (Azadirachta indica) to soil P concentration and mycorrhizal colonization. Arid Land Res Manag 7:327-333.

Harley JL, Smith SE (1983) Mycorrhizal Symbiosis. Academic Press, London, 483 pp.

Jackson ML (1973) Estimation of Phosphorus Content. Soil Chemical Analysis. Printer Hall Inc., New Delhi.

Jeffries P (1987) Use of mycorrhizae in agriculture. Crit Rev Biotechnol 5:319-357.

Johnson NC, Graham JH, Smith FA (1997) Functioning of mycorrhizal associations along the mutualism-parasitism continuum. New Phytol 135:575-585.

Koomen I, Grace C, Hayman DS (1987) Effectiveness of single and multiple mycorrhizal inocula on growth of clover and strawberry plants at two soil $\mathrm{pH}$. Soil Biology and Biochemistry 19:539-544.

Kumar PP, Reddy SR, Reddy SM (2000) Mycorrhizal dependency of some agroforestry tree species. Indian Forester 126:397-402.

Mallesha BC and Bagyaraj DJ (1990) Effect of staggered inoculation of growth medium with Glomus mosseae and Rhizobium on Leucaena. In: Bagyaraj DJ and Manjunath A (eds) Mycorrhizal symbiosis and Plant Growth. Karnataka, Bangalore, pp 104-106.

Michelsen A (1992) Mycorrhiza and root nodulation in seedlings from five nurseries in Ethiopia and Somalia. For Ecol Manag 48:335-344.

Michelsen A (1993) Growth improvement of Ethiopian acacias by addition of vesicular-arbuscular mycorrhizal fungi or roots of native plants to non-sterile nursery soil. For Ecol Manag 59:193-206.

Miller RM, Jarstfer AG, Pillai JK (1987) Biomass allocation in an Agropyron smithi-Glomus symbiosis. Am J Bot 74:114122. 
Mohan V, Verma N (1995) Studies on vesicular-arbuscular mycorrhizae association in seedlings of forest tree species in arid zones of Rajasthan. In: Adholeya A, Sujan S (eds) Mycorrhizae: Biofertilizers for the Future. TERI, New Delhi, pp 52-55.

Muthukumar T, Udaiyan K, Rajeshkannan V (2001) Response of neem (A. indica A. Juss) to indigenous arbuscular mycorrhizal fungi, phosphate-solubilizing and asymbiotic nitrogen-fixing bacteria under tropical nursery conditions. Biol Fert Soils 34:417-426.

Olsen SR, Cole CV, Watanabe FS, Dean LA (1954) Estimation of available phosphorus in soils by extraction with sodium bicarbonate. United States Department of Agriculture, Circ n. 939.

Pande M, Tarafdar JC (2004) Arbuscular mycorrhizal fungal diversity in neem-based agroforestry systems in Rajasthan. Appl Soil Ecol 26:233-241.

Phillips JM, Hayman DS (1970) Improved procedures for clearing roots and staining parasitic and vesicular-arbuscular mycorrhizal fungi. Trans Br Mycol Soc 55:158-161.

Prasad K (2002) Effect of Arbuscular mycorrhizae on biomass yield, uptake and translocation of nitrogen, phosphorous, potassium in $A$. indica. In: Manoharachary C, Purohit DK, Reddy SR, Singaracharya MA, Girisham S (eds) Frontiers in Microbial Biotechnology and Plant Pathology. Scientific Publishers, Jodhpur, pp 187-191.

Porter WM (1979) The most probable number method for enumerating infective propagules of vesicular-arbuscular mycorrhizal fungi in soil. Aust J Soil Res 17:515-519.

Rajan SK, Reddy BJD, Bagyaraj DJ (2000) Screening of arbuscular mycorrhizal fungi for their symbiotic efficiency with Tectona grandis. For Ecol Manag 126:91-95.

Reena J, Bagyaraj DJ (1990) Growth stimulation of Tamarindus indica by selected VA Mycorrhizal fungi. World J Microbiol Biotechnol 6:59-63.

Satir GR, Duniwav JM (1982) Evaluation of plant response to colonisation by VA-mycorrhiza fungi. B. Environmental variables. In: Schenck SC (ed) Methods and Principles of MycorrhizaI Research. American Phytopathological Society, St Paul, pp 77-80.
Schenck NC, Perez Y (1987) Manual for the Identification of VA Mycorrhizal Fungi. Second Edition. International Culture Collection of VA Mycorrhizal Fungi (INVAM). University of Florida, Gainesville, 286 pp.

Sharma MP, Adholeya A (2000) Response of Eucalyptus tereticornis to inoculation with indigenous AM fungi in a semiarid alfisol achieved with different concentrations of available soil P Microbiol Res 154:349-354.

Smit SE, Read DJ (1997) Mycorrhizal Symbiosis. 2nd Edition. Academic Press, San Diego and London, 605 pp.

Smith FA, Smith SE (1997) Structural diversity in (vesicular)arbuscular mycorrhizal symbioses. New Phytol 137:373388.

Smith FA, Jakobsen I, Smith SE (2000) Spatial differences in acquisition of soil phosphate between two arbuscular mycorrhizal fungi in symbiosis with Medicago truncatula. New Phytol 147:357-366.

Srinivas K, Shanmugam N, Ramaraj B (1988) Effect of VAM fungi on growth and nutrient uptake of forest tree seedlings. In: Mahadevan A, Raman N, Natarajan K (eds) Mycorrhiza for Green Asia. Madras University, Madras, pp 294-297.

Sumana DA, Bagyaraj DJ (1999) Selection of efficient VAmycorrhizal fungi for inoculating Neem. In: Proceedings of the National conference of Mychorrhiza. Singh S (ed) Barkatulla University, Bhopal, pp 10.

Tewari DN (1992) Monograph on neem (Azadirachta indica A. Juss.). International Book Distributors, Dehradun.

Urgiles N, Loján P, Aguirre N, Blaschke H, Günter S, Stimm B, Kottke I (2009) Application of mycorrhizal roots improves growth of tropical tree seedlings in the nursery: A step towards reforestation with native species in the Andes of Ecuador. New Forests 38:229-239.

Vasanthakrishna M, Bagyaraj DJ, Nirmalnath PJ (1994) Responses of Casuarina equisetifolia to inoculation with Glomus fasciculatum and/or Frankia. For Ecol Manag 68:399-402.

Walkley A, Black IA (1934) An examination of Degtjareff method for determining soil organic matter, and a proposed modification of the chromic acid titration method. Soil Sci 37:29-38.

All the content of the journal, except where otherwise noted, is licensed under a Creative Commons License CC BY-NC. 